\title{
Mad studies and social work: Conceptualising the subjectivities of service user/survivors who experience significant mental health problems
}

\author{
Stephen J. Macdonald ${ }^{1}$, Anne Charnock ${ }^{2}$, Jane Scutt ${ }^{3}$
}

\begin{abstract}
This article draws on contemporary and classical psycho-political theorists to conceptualise 'mental illness' as a social construct. The research employs a Mad Studies and anti-psychiatry perspective to reframe 'mental illness' from an individualised pathological defect to a socially constructed reality (Foucault, 1967; Menzies et al., 2013). The study applies a qualitative biographical methodology to analyse the subjectivities of people with severe mental health problems, their family members and mental health practitioners. In this study, once individuals were conceptualised as pathologically 'ill' they were then medicated and often institutionalised as a form of 'treatment'. The findings present a theoretical analysis of participants' subjectivities to examine historic and contemporary psychiatric practices. The article will conclude by discussing how Mad Studies can offer social work practice an alternative theoretical standpoint to conceptualise 'mental illness' as a social rather than a pathological phenomenon.
\end{abstract}

Keywords: mad studies; anti-psychiatry movement; 'mental illness'; biographical methodology; institutionalisation; medicalisation; family

1. Reader in Social Science, University of Sunderland

2. Principal Lecturer/Team Leader Social Studies, University of Sunderland

3. Senior Lecturer in Social Work, University of Sunderland

Address for Correspondence: Dr. Stephen J. Macdonald, School of Social Sciences, Faculty of Education and Society, University of Sunderland, The Reg Vardy Centre, St Peter's Way, Sunderland, SR6 ODD. Stephen.j.macdonald@sunderland.ac.uk

Date of first (online) publication: 2nd October 2018 


\section{Introduction}

The aim of this article is to critically evaluate the psychiatric notion of 'mental illness' from an anti-psychiatry and Mad Studies theoretical perspective. In psychiatric practice the concept of mental distress has been entirely pathologised. Conditions such as anxiety, depression, bipolar and schizophrenia are conceptualised through a disease model, where problems associated with these disorders are firmly situated within a person's dysfunctional biochemistry. From this perspective, behaviour can be understood through a normative objective scale ranging from 'rational' to 'delusional'. Any behaviour that deviates from current social norms, i.e. what is considered 'rational', is observed and identified as signs and symptoms of underlying mental 'illnesses' (Szasz, 2007; LeFrancois et al., 2013). By engaging with psychopolitical theory emerging from Mad Studies, this article critically examines the pathological explanations of mental distress in contemporary mental health services, by analysing the narratives of service users/survivors, their family members and mental health practitioners.

This article presents the subjective experiences of individuals who have experienced mental distress, alongside the narratives of mental health practitioners and family members, using a biographical research methodology. Participants have been diagnosed with a range of mental health issues including depressive disorders, bipolar disorders and schizophrenia. These service user/survivor narratives are supplemented with the experiences of family members and practitioners over the same timeframe. In an attempt to critically evaluate the pathological explanations of mental distress, this article draws on the work of anti-psychiatry and Mad Studies theorists to present a critical explanation of mental health (Goffman, 1961; Laing, 1967; Foucault, 1967; LeFrancois et al., 2013; Faulkner, 2017). Therefore this article offers a critical position for contemporary mental health services to offer social work practitioners an alternative lens to guide social work practice.

\section{The medicalisation of emotional responses to the socio-cultural environment}

Within mental health practice, the psycho-political ideas that emerged from the anti-psychiatry movement are considered by psychiatry as a failed project of the mid-to-late 20th century (Semple and Smyth, 2013; Sedgwick, 1987). Within contemporary psychiatry the key critiques of this movement refer to its lack of empirical evidence to support claims that mental illness is a social, rather than pathological, phenomenon. As the vast majority of theoretical knowledge from the anti-psychiatry movement arose from single case studies or observational research presenting subjectivities, their findings have been methodologically dismissed by 
contemporary psychiatry (see Semple and Smyth, 2013). This is due to medicine's fundamental certainty in the tradition of quantifiable findings from an empirical positivist perspective (Cowen et al., 2012; Porter, 2006). The dismissal of psychopolitical theorists in contemporary psychiatry is illustrated by David Semple and Robert Smyth in the Oxford Handbook of Psychiatry (2013), as they suggest:

Although the central arguments of the anti-psychiatry movement have largely been discredited in mainstream scientific literature, they have retained currency in some areas of the popular press, within some patient organisations, and in certain religious cults. They are presented here for historical interest and so that sources of modern-day advocates of these ideas can be identified.(Semple and Smyth, 2013, p. 24)

Within this handbook, used by trainee psychiatrists in the UK, disorganised, highly stressed and harmful behaviours are categorised into specific diagnoses, which are explained through the concept of pathological dysfunction. Hence, a biomedical model is applied by the authors to understand an individual's behaviour and their emotional responses to their external environment. This narrative is indicative of the aims of contemporary psychiatry to conceptualise mental distress as a pathological neurological dysfunction. Psychiatry explains why individuals experience periods of 'delusional thoughts', increased levels of anxiety or feelings of depression through the concept of pathology rather than because of social and structural harms (see the DSM-5 (APA, 2013)). Contemporary psychiatry claims that it can diagnose a condition, predict the development of it (i.e. prognosis), and prescribe treatments with its growing toolkit of psychotropic/psychoactive drugs (Cowen et al., 2012; Menzies et al., 2013). From this perspective, mental distress can be pathologised and treated with medication in the same way as a physiological condition such as asthma, diabetes or HIV (Szasz, 2007).

The problem with this biomedical perspective is that explanations of mental distress are imbedded within individuals' biochemistries (Cowen et al., 2012; Menzies et al., 2013). Psychiatry explains mental health conditions from an individualised perspective concerning defective pathologies, rather than through a social-emotional response to an individual's external environment. Since the 1980s we have seen an increase not only in people being diagnosed with conditions such as depression, schizophrenia or bipolar disorder, but there has also been the 'discovery' of new conditions, added to the toolkit of psychiatrists. An example of this is the expansion of the DSM-5 diagnostic manuals used by western psychiatry. The pervasiveness of the biomedical model means that not only is mental distress defined through the medicalised construct of 'mental illness', but this ideology has also become the dominant discourse for describing feelings of anxiety and distress within contemporary western societies (Menzies et al., 2013; Esposito \& Perez, 2014).

In the 21 st century psychiatry has become the dominant discipline which defines professional practice for service users/survivors experiencing mental distress 
(LeFrancois et al., 2013). The key conceptual problem with psychiatric services is that service user/survivor voices are dismissed as either symptomatic of a person's 'mental illness', or on the grounds of safeguarding based on risk factors to a person's well-being. As Menzies et al. (2013) illustrate, Mad Studies unites scholars from the mad pride and the anti-psychiatry movements to represent service user/survivor perceptions and their lived experiences of mental distress. The emergence of Mad Studies as a critical perspective has challenged the dominance of contemporary psychiatry and the practices employed in mental health services (Lewis, 2017; Kafai, 2013; Menzies et al., 2013).

Within Mad Studies, the rejection of the biological explanation for mental health problems does not make mental distress any less 'real', but explains this phenomenon as resulting from socio-cultural experiences rather than due to pathological dysfunction (Kafai, 2013; LeFrancois et al., 2013). The rejection of this biomedical model of mental distress is illustrated in the work of Thomas Szasz. Szasz (2007) suggests the term 'illness' is used in medicine to describe a pathological disease, such as a bacterial infection. When applying this concept to 'mental illness', he suggests that there is no scientific evidence that 'mental illness' is caused by a biological condition (Szasz, 2007). According to Szasz there are only a handful of mental health conditions which are understood to be caused by a biological or neurological infection (Szasz, 1961; 2007). When applying the discourse of mental illness, 'illness' becomes a metaphor to describe mental 'breakdown' caused by social factors resulting in mental distress.

Within Mad Studies, implying that 'mental illness' is a construct does not deny the impact that mental distress has on a person's subjective experiences, but it does suggest that this is due to social conditions (Kafai, 2013). For individuals that experience severe forms of mental distress, such as depression, it can lead a person to engage in harmful behaviours such as self-harm or suicide (Szasz, 1961; 2007). For Szasz, the answer is not to prescribe pharmaceutical solutions, i.e. psychotropic/ psychoactive medications, which alter a person's neurological bio-chemistry, but to treat these conditions within the social environment (Szasz, 2007). Therefore, it is the socio-cultural which is the problem, not the pathological, if one is to understand the escalation of mental distress within contemporary society (Szasz, 2007).

\section{The psycho-political conceptualisation of 'self'}

As Kafai (2013) illustrates, psychiatric services are constructed through binary opposites where healthy individuals are conceptualised through behavioural normalcy and people defined as mentally ill are constructed as defective. Faulkner (2017) suggests these pathological behavioural defects cannot be directly measured, but are justified through a 'proxy' measurement in psychiatric services. As she 
states, these proxy measurements consist of 'diagnostic frameworks, scales and questionnaires that rely on people self-reporting their feelings, symptoms and behaviours ... In reality, few people fall easily into one diagnostic category' (Faulkner, 2017, p. 502). From this perspective, 'mental illness' may be more accurately described as the experience of mental distress which has a significant and disabling impact on everyday life.

Menzies et al. (2013) suggest that the critical framework that has emerged from Mad Studies has been significantly influenced by mad activists and anti-psychiatry scholars. Anti-psychiatry scholars such as Erving Goffman and R.D. Laing have previously proposed alternative interactionalist perspectives to critique the binary nature of the biomedical model. Scott and Thorpe (2006) illustrate similarities concerning the writings of Laing and Goffman from a micro interactionalist perspective when conceptualising service user/survivor experiences of mental distress. For Goffman, mental distress is conceptualised through interaction and performance, which is defined by external environmental factors (Goffman, 1959; 1961; 1964).

According to Goffman, human behaviour can be understood as a set of performances which individuals learn and act out within a range of social settings. Socialisation takes place through individuals learning multiple rituals which they perform within everyday life (Goffman, 1959). These symbolic performances are shaped by the institutional environments within which they take place. People perform and act out their learnt rituals within their family environment, their local communities, within education, at hospital, etc. (Goffman, 1959; 1961). For Goffman, humans perform like actors within their socio-cultural environments, yet, although each human is an actor, they also simultaneously act as the audience for other people's performances. These performances are complex in nature and are culturally and historically specific (Goffman, 1959; 1964).

Scott and Thorpe (2006) suggest that by examining some of Goffman and Laing's core principles regarding mental health it is possible to develop a constructionist, rather than a pathological, explanation for mental distress. For Laing, modernity constructs the notion of normality, with reference to behaviour, based on its contradictory notions of morality. He suggests that we live in a society which is underpinned by insecurities, contradictions and inequalities (Laing, 1959; 1967), and these contradictions manifest themselves within the family (and other social institutions, such as schools), where children learn socially approved thoughts and feelings which construct their adult subjectivities (Laing, 1971). The vast majority of people develop strategies to cease noticing these social and cultural contradictions, but for some individuals the recognition of these contradictions can manifest itself in the experience and subjective performances of mental distress (Laing, 1967; 1971).

Similarities can be made between Laing and Goffman with reference to how they both theorise human interaction through the concept of performance (Scott and Thorpe, 2006). For Goffman, performance is linked to the backstage self who has a 
level of control over its interactions; yet, for Laing, it is when the individual's backstage self loses control over their performances that the result is what we now define as 'mental illness' (Laing, 1967). According to Laing, the loss of external control results in an individual developing strategies to protect the internal existential self from the external harmful world. During this process many individuals' subjectivities become lost in the external contradictory performances of everyday life (Laing, 1967). From this perspective, the binary assumptions of 'mental illness' disappear in the contradictory and often harmful social environments individuals find themselves existing within. Therefore mental distress can be understood as emerging not from a person's pathological 'defects', but in the past and present everyday experiences of service users/survivors (Kafai, 2013; Faulkner, 2017).

\section{Mental distress, discipline and govern}

With the recent emergence of Mad Studies as a critical examination of psychiatric practices, the work of Michel Foucault has been drawn on as a source of knowledge when examining the disciplinary nature of psychiatry (Menzies et al., 2013). Although theoretically Foucault's philosophical standpoint, i.e. the importance of discourse, is radically different from the other anti-psychiatry scholars such as Laing and Goffman, similarities emerge with reference to the 'symbolic' meanings of 'mental illness' through the management/governance of normality. From a Mad Studies perspective, by linking these different theoretical perspectives Foucault's analysis conceptualises mental distress from a macro standpoint, whereas Goffman is concerned with the micro rituals in everyday life.

Foucault suggests that the cultural acceptance of mental distress as a biological 'illness' is a system of disciplinary power. This form of disciplinary power is applied to preserve the moral order in the modern and late-modern periods. For Foucault, psychiatry develops as a dominant professional discipline to treat people experiencing mental distress, not because it was/is effective in understanding the aetiology of 'mental illness', but because it governs western moralities (Foucault, 1967; Scull, 2014). Foucault (1967) suggests that the fear of 'madness' and the fear of the 'mad' has become a dominant and symbolic discourse of social control. From this perspective the rebellious individuals (i.e. the 'mentally ill') are transformed into the docile (respectable) citizens of the masses through psychiatric treatments (Foucault, 1977). To maintain social morality institutions construct multiple selfgoverning discourses that regulate and reinforce cultural norms and dominant ideologies at any one given time.

Within Mad Studies the work of Foucault has significantly influenced the critique of contemporary psychiatry (Kafai, 2013; Menzies et al., 2013). For Foucault, the body is a political entity, which is disciplined and self-serving to cultural norms 
within any given social system (Foucault, 1977). Applying a Foucauldian approach to contemporary society, psychiatry is positioned as a key enforcer of neoliberal values in late-modernity. At the beginning of the 21st century psychiatry has developed an effective form of disciplinary machinery in a post-institutional care environment through pharmaceutical treatments. These medications, although ineffective in curing the 'illness', are an effective tool in regulating the emotional impact of mental distress. This provides a quick-fix solution to social problems, allowing people to cope with the stresses of neoliberal society and maintain cultural moralities (Esposito \& Perez, 2014).

\section{Mad studies and social work}

Theoretically this article will examine how mental distress can be conceptualised from a constructionist perspective using psycho-political scholars from the antipsychiatry and Mad Studies movements. This article will suggest that applying these approaches to contemporary mental health practice can offer an alternative constructionist interpretation to mental distress, rather than the dominant individualistic approach of psychiatry. By applying these radical theoretical perspectives to social work, social work practitioners are allowed an alternative theoretical lens through which to understand mental distress as a sociological rather than a pathological phenomenon. As Deacon (2017) illustrates, social work is a discipline that is influenced by a diverse number of theoretical perspectives ranging from neoliberal individualism to radical constructionism. She suggests that social work theory is inefficient if it is only applied to understand service users' behaviour. As Deacon (2017, p. 10) suggests, 'a social worker ... needs to be able to intervene in a person's life and this intervention should be underpinned by theory'.

Mad Studies and anti-psychiatry scholars not only offer an alternative theoretical perspective for social work, but this is accomplished in partnership with mental health survivors. As Faulkner (2017, p. 512) states,

'Telling our [service user/survivor] stories and listening to each other's stories is the cornerstone of peer support, empowerment and recovery. But it is also a political act and begins the process of creating and building our experiential knowledge'.

From Faulkner's perspective, experiential knowledge is fundamental in improving services and confronting discrimination and social oppression. To present social work with an alternative theoretical lens into mental health practice, the findings section will conceptualise the subjectivities of long-term mental health service users/survivors, together with the experiences of their family members and mental health practitioners. 


\section{Methodology}

By comparing service user/survivor perceptions with family and practitioner observations of historical and contemporary services, the study's intention is to comprehend the biographical experiences of having a long-term mental health condition. This qualitative study analyses the biographical narratives of people with mental health conditions in an attempt to compare changes in care services, from confinement to contemporary support within a community setting, using Bertaux's (2003) biographical interviewing technique. Semi-structured interviews lasting between thirty minutes and two hours were undertaken; this approach asks only a small number of focused questions relating to participants' life experiences. By limiting questions, this produced a biographical narrative that gave more control to the participant and restricted the interviewee from being drawn into a structured hierarchy (Wengraf, 2001). The importance of this form of interviewing is that participants were allowed to start their life story at any historic point they chose. This enabled them to speak freely about their position in relation to the research issue raised. It also allowed participants to translate their own events, themes and meanings within their own biographies to produce a narrative form.

In total sixteen participants were interviewed, consisting of nine service users/ survivors, three family members and four mental health practitioners. The study employed a snowball sample where information was sent out to local health and social care services in the North-East of England to facilitate recruitment. A number of social work/social care/nursing practitioners helped the research team promote the study in order to recruit service user/family volunteers. Service users/survivors were recruited who had experienced hospitalisation because of a diagnosed mental health condition. They had all experienced long-term hospitalisation between 1975 and 2014, which was defined in this study as a minimum six month period in hospital. All service users/survivors were still receiving support due to their longterm mental health conditions. The age of service users/survivors ranged from 55 to 71 years. All service users/survivors were from a white ethnic background and more male service users/survivors $(n=6)$ were interviewed compared to females $(n=3)$. The majority of service users/survivors were from traditional working-class backgrounds $(n=8)$ with one participant defining himself as middle-class.

The mental health practitioners had been employed within a mental hospital before or during the implementation of the Mental Health Act (1983). They had actively worked in health or social care services during the 1990s, and had witnessed the transition of hospital-based care to community care services. With reference to the practitioner group, two female participants were from a white ethnic background and two male practitioners were from black/Asian ethnic minority communities. The majority of practitioners described growing up in a traditional working-class setting $(n=3)$ with one participant indicating that they were from a middle-class family. Finally, all family members who were included in the study had actively visited and/ 
or been part of supporting a close family member throughout their time as a service user. The age of family members ranged from 50 to 72 years. Two of the female family members were from a white ethnic background and one male family member was from a black ethnic minority community. All family members interviewed could be defined as growing up within a traditional working-class community. Interviews in the study took place in 2014-2016, in the North-East of England.

A phenomenological approach was used to interpret the biographical narratives of participants in this study (Kafai, 2013). The study presents participants' interpretations of their life events to situate the analysis from a service user/survivor perspective. By applying Daniel Bertaux's (2003) methodology to service users' biographical narratives, the findings explored personal experiences of social change (Kafai, 2013; Bertaux, 2003). N-vivo was used to help organise the data in order to apply a thematic analysis to the research. However, this study has a number of limitations due to its small sample size, therefore, the research does not claim to be representative of any group outside of the sample. To protect the identities of all individuals in this study, pseudonyms are used throughout the findings section of this article. Full ethical approval was gained by the research team from the host university as well as through the relevant health and social care organisations before the research commenced.

It should be noted that there were a number of intersectional relationships that emerged with reference to gender and social class, which shaped the narratives presented in the findings section. Although service users'/survivors' experiences of hospitalisation were similar, the two female service users/survivors still had contact with their families and received regular visits when in hospital or housed in residential care. This was not the case for any of the male participants in this study. The most significant intersectional relationship which impacted on service users'/ survivors' lives related to their socio-economic status. The majority of the group described themselves as working-class, and experienced high levels of poverty and deprivation within their life stories. Hence, the narratives that follow are framed by these experiences of poverty and deprivation, which are interrelated with their experiences of disability.

\section{Methodological challenges}

When conducting the research a number of difficulties occurred, particularly around accessing service user/survivor groups. The study aimed to collect the biographical narratives of individuals who had experienced severe mental distress in a pre- and post- (de)institutional care setting (pre- and post-Mental Health Act 1983). These were older service users who were not predominantly involved in local activist community groups. It was realised very early in the study that it seemed very few health and social care organisations were actively attempting to recruit service 
users/survivors for this study. Hence a key barrier was a lack of access to research participants from our targeted population. Then, once we had access to a sample and conducted the biographical interviews, unfortunately a number of participants had to be excluded from the sample as their life stories did not fall into our targeted population (i.e. one participant did not have a mental health condition and another had not experienced hospitalisation). This reduced our sample further to just nine service users/survivors. We also discovered that many service users'/survivors' memories of hospitalisation were somewhat fragmented. This was explained due to an increased use of medication when in hospital. To overcome this problem we decided to support the experiences of service users/survivors with the memories of their family members and key practitioners. This presented us with yet another methodological problem, as Mad Studies must represent the voices of service users/ survivors and not the voices of other individuals, who may have contributed to a participant's oppression. We overcame this problem by the team deciding that we could still incorporate the narratives of family members and practitioners as long as they were used only to assist the experiences of service users/survivors in this study.

\section{Findings: Families, ideology and the fragmented Self}

Within the work of Laing (1971), family dynamics becomes an essential part of the socialisation process. It is in the family unit where performances are leant, but where they can also become fragmented. From this perspective the family becomes a focal point of social ideological conflict, where socially constructed identities are formed through a complex system of social contradictions. The family becomes central to how individuals learn their social roles and start constructing what Goffman (1959) would refer to as the 'performance of self'. Within this study a number of participants referred to very painful and often traumatic upbringings, and these narratives often involved significant and ongoing experiences of violence within the family home. An example of this is described by Harry, who had a relatively stable relationship with his mother and a violent and unstable relationship with his father. Harry describes his relationship with his father as founded on extensive periods of mental and physical abuse. In one incident Harry describes:

My mum was alright, but my dad was a drunkard and he used to pick on us all the time.

[He] tried to choke us to death one day on the kitchen floor. [He would] come in drunk and just pick on us for no reason. (Harry: servicer user/survivor)

Harry describes experiencing systematic forms of abuse throughout his childhood which often resulted in violent interactions. Domestic violence seems to have been somewhat normalised in Harry's household. Within Harry's narrative, alcohol 
played a significant role in his experience of violence. The fear of his father coming home whilst under the influence of alcohol was a significant stress factor throughout Harry's childhood. He suggests that significant contradictions appeared within his loving relationship with his mother, as he perceived that she was unable to protect him from the violence he experienced within the family home. The death of his father led Harry into a significant mental 'breakdown' which manifested into him experiencing long-term mental distress. Within Harry's narrative we can view how 'love' operates through the actions of violence, where nurturing and family relations are formed through the contradiction of domination and control (Laing, 1971).

It should be noted that not all participants discussed experiences of domestic violence, violence or abuse within their childhood or adolescent years. Five of the service user/survivor participants discussed having what they would describe as a relatively happy childhood. Although early childhood experiences were reported as being happy and nurturing, it is the family unit that seems to become an allencompassing environment for some of the service users/survivors. An example of this can be seen in Jack's biographical narrative. Jack reports that even when his parents were alive he had only one person who he referred to as a friend. He suggests after becoming unemployed he struggled with having any form of meaningful relationship other than with his mother, as Jack states he did not have any form of 'social life'. Jack refers to his family home as an 'institution'.

I had one friend that was quite close and she kind of came round quite often and she would sit with us ... I didn't literally have like a social life. Do you know what I mean? I had one friend that was coming round and we'd sit in my bedroom and we'd talk and crack on... That [my bedroom] was almost more of an institution, in a sense or just as much of an institution because of what I was going through, as what the hospital was. So I was basically going from one institute to another institute. (Jack: service user/survivor)

During this period of his life-history Jack reports that there were long periods of time where he did not leave his bedroom. As he got older he lost contact with his friend, and this resulted in Jack's only contact with the outside world being through his mother. Although it could be suggested that Jack took refuge within his family home, this safe space over time seems to have restricted his social interactions and isolated him from his wider community. When Jack's mother died the protection of the family unit was removed and it had a significant impact on the escalation of his mental health problems. It is during this period where Jack refers to the onset of depression, which would eventually lead to him becoming hospitalised. Jack suggests that he has never truly got over the death of his mother. For Laing it is this loss of 'self' which is significant in the onset of mental distress. The links between emotional ideological conflicts within the family were also illustrated by some of the health practitioners in this study. Christopher, a nurse practitioner, refers to a number of patients whose identities were significantly affected by cultural ideologies 
emerging within the family unit. In one example Christopher highlights the impact that this emotional conflict has on one of his patients:

This one particular patient in the secure unit, he was a wired-up very anxious boy... Then his dad came to visit him and I remember hearing this discussion ... And I'm thinking, 'F--g hell. ... Not surprising he wants to be in hospital' ... There was nothing wrong with him anymore. He needed to go home but he would do things to stop himself being discharged. It seemed to me ... his father's a neo Nazi ... and I think this boy's a bit sensitive and maybe ... his father should be in here for treatment and maybe his son should be at home with a bit of love and care. (Christopher: mental health nurse)

Christopher highlights the significance of the family as an ideological space which affects the performances of his patient. He makes links between the sociocultural environments that shape the family and the mental distress experienced by his patient, which in this case resulted in ongoing hospitalisation. Christopher makes associations between the social and cultural stresses that his patients have experienced and their hospitalisation, which occurs because of these environmental factors. He suggests that the concept of physical or emotional abuse was a significant risk factor, which led to many of his patients becoming hospitalised.

\section{Discipline and control through medication}

From a Foucauldian perspective, individuals whose behaviour deviates from dominant cultural moralities are subject to institutional power exercised by an array of psychiatric practitioners (Foucault, 2003). Traditionally, professional power would have been concentrated within particular institutional settings; however, with the expansion of the clinic into the community, power is exercised through use of new technologies (i.e. with medications). Within this study it was psychotropic/ psychoactive medication, which became an essential form of treatment, both outside in the community and inside within institutional care.

Medication was discussed by all participants, whether they were service users/ survivors, family members or practitioners. All three groups discussed concerns about the effectiveness of long-term medication and its ability to reduce or cure mental 'illnesses'. Interestingly, it was practitioners and family members who were far more critical of medication than service users/survivors. No family members interviewed entirely agreed that medication was beneficial for their family member. None of these participants considered medication as a useful long-term treatment to reduce or to cure symptoms of mental distress. Donna's family recalled how the use of medication was significantly more obvious during periods of hospitalisation. One particular incident during a period of hospitalisation is reported by Pauline: 
And when we saw her she was like a zombie ... because she's very talkative and loud and she wasn't like that. She was as though her eyes were dead. She hardly spoke. She was just not her and I remember my Mum saying, 'Oh must be the tablets she's on. They've calmed her down', which in a way was good [laughs] to us because she had been so awful before she'd gone in, but then it wasn't her. ... She was always pleased to see us and she knew who we all were, but ... she was just down and very calm but like a zombie. (Pauline: family member)

Pauline acknowledges that Donna's behaviour was extremely destructive, and on occasions violent, and she would often end up in hospital because her social performances were 'out of control'. But, as Pauline states, although her violent outbursts had gone the side-effects of this medication transformed her personality. When Donna's family describe these periods of hospitalisation, they do not conceptualise the use of medication as a treatment to 'cure' her 'illness'. From their perspective medication was used to normalise her behaviour. Although family members were generally critical of medication, service users/survivors were committed to the idea of this type of treatment. All service users/survivors had taken a wide range of psychotropic/psychoactive medications, and service users/survivors described easy access to medications via their GPs and for the duration of their stays in psychiatric units/hospitals. From Harry's perspective, receiving treatment using psycho-pharmaceutical medications was standard practice:

I used to take tablets all the time. Medication was easy access. I would get them off the doctor, three months' supply, but they've cut us down now to a month, because I still get suicidal thoughts. (Harry: service user/survivor)

One of the key issues Harry discussed was feelings of loneliness and isolation, which often led to self-harm and suicide attempts. For this reason Harry is prescribed a range of medications to treat his condition, referred to as schizophrenia. His suicidal tendencies are a key concern and a vital symptom of his condition. Although Harry has been using medication since his early teenage years, he still reports suicidal feelings. Although recently he has reported an increase in suicidal urges, his medication and treatment has not changed, except for a reduction from threemonthly to monthly prescriptions. For Harry, issues of loneliness, which is central to his biographical narrative, have not been dealt with or even acknowledged. When Harry reports an increase in mental distress to his GP, this leads to an increase in observational disciplinary techniques through restricted access to his medication. Alternatively, if participants raised concerns about their medication and requested a reduction, this seemed to be disregarded. In fact this request occasionally had the opposite effect, as William reports:

I said [to the GP] 'I don't think these medications are doing me any good at all', and he said, 
'Well would you like to go and see Professor Pearson at the [hospital]?', which I did. And he [Professor Pearson] said, 'What dosage of lithium are you on?' And I said, 'I'm not'. So he said, 'Right. You are on it now.' (William: service user/survivor)

None of the service users/survivors critically discuss the use of medicine or other forms of therapy such as ECT; within this study all service users/survivors accepted the need for psycho-pharmaceutical medications. Like a diagnosis, service users/ survivors perceived medications as successfully treating their feelings of mental distress. Hence, medication as a system of disciplinary power was regulated not just by practitioners but also by service users/survivors themselves. This concept of selfdiscipline can be viewed in Jason's narrative where, although he conceptualises these forms of treatment as effective, he also states that he very rarely leaves his nursing home. For Jason, his key interactions consist of his relationship with medical and social care staff, such as mental health nurses, psychiatrists or residential carers, as can be observed in his narrative:

The nurse used to give us injections which are supposed to be for schizophrenia I've been told. The doctor said I have schizophrenia ... Last week the doctor was here and I think things have improved a little bit. To be honest with you, I've had electric shock treatment as well. (Jason: service user/survivor)

Although Jason suggests that he feels his condition has improved, particularly over recent weeks, he struggles to explain why he thought this was the case. The relationship of 'trust' with health and social care practitioners was important to many of the service users/survivors. Jason's narrative is representative of other service users/survivors who were content to conform to routine institutional activities, where medication seemed to be used to influence behaviours, rather than to 'cure' their conditions. This can be viewed when exploring practitioners' perspectives of medication, as they are open about the benefits of psychotropic/psychoactive medicines for normalising behaviour. Johnny, who started his career as a mental health nurse and progressed into a senior health role, discussed the revolution of psychiatric medication within his professional practice. As he reports:

Patients who had psychosis, you used an anti-psychotic. In particular chlorpromazine which ... was gradually replaced ... the chlorpromazine because of the major side-effects with the first generation of anti-psychotics. Modecate, depixol, and now we have the atypical antipsychotics. And then people getting treatment for depression, the tricyclics, and all these drugs. ... Medications, we [health practitioners] are sceptical whether they work or not but at least they delay the process. (Johnny: senior health professional)

Johnny raised a number of concerns relating to, in his words, a 'strong medical model' approach regarding mental health. Johnny illustrates that the use of 
medication was fundamental throughout his practice 'treating' mental health patients. When discussing changes in pharmaceutical procedures, he suggests that many of the changes to anti-psychotic medications were because of significant side-effects experienced by patients. He also acknowledges that he is sceptical of whether these medications are effective in treating 'mental illness'.

Although there was scepticism concerning the effectiveness of psychoactive/ psychotropic medications, they were still described as the most common form of treatment by mental health practitioners. Kelly, a mental health therapist, also illustrates how all of her clients are prescribed some form of medication to treat their mental distress. Kelly suggests that, in her experience when meeting with a service user/survivor for the first time, the service user/survivor always focuses on their diagnosis and which medication they are currently taking. As Kelly suggests:

Service users will come in and say, 'Well this is my diagnosis and this is my tablets what I'm on'. And then we were saying... It's not about your medication because you've got a care package in place and people could work with you around that. We're working with you around what you want to achieve, what you want to get out of coming to the project. Yeah. But it was like, 'What? But my medication and I've got schizophrenia'. (Kelly: mental health therapist)

From Kelly's perspective, it seems that medication verifies the reality of a particular 'illness' for service users/survivors. She suggests that service users/survivors also conceptualise their difficulties through the notion of pathological 'illness' and conceptualise this as the cause of why they struggle in general day-to-day life. For service users/survivors, by accepting they are 'suffering' from an 'illness' they may be exercising a form of psychiatric disciplinary power. It seems that psychiatry offers service users/survivors the promise of normality where their experiences of mental distress can be eradicated with medication, yet this is a long term commitment, rather than a short-term solution, as participants in this study had been taking medication for approximately 30 to 50 years.

\section{Contemporary Care}

In the work of Goffman (1961), mental hospitals are seen as disciplinary systems that have an effect on all forms of interaction, which he refers to as 'total institutions'. In contemporary health and social care services it has been claimed that long-term institutional care has ended within the UK (Kelly and McKenna, 2004). Yet Szasz (2005) suggests that this is a misconception, as although the large mental hospitals have closed these have been replaced by smaller care institutions. In this study only two service users/survivors were living in their own rented accommodation, whereas seven were living in some form of residential care. Furthermore, the entire 
population of service users/survivors had repeatedly been involuntarily detained and admitted into psychiatric hospitals for a range of intermediate periods. Both service users/survivors and care practitioners described very mixed experiences of working and living in different residential care units.

A number of service users/survivors who had lived in smaller care units have described their experience as positive. Jude's narrative is comparatively representative of the experiences of other service users/survivors living in residential care. Although he previously described experiencing intimidation and restraints in a previous residential care unit, Jude now portrays a good relationship with staff and comfortable living conditions. But while Jude describes his current living conditions as positive he does also acknowledge that he very rarely leaves his residential care home. Jude was unable to explain why he does not go outside anymore, even though he states that he would like to do so:

I've had a good time. Yes. I like them all. I've had a good life. I've enjoyed meeting people. There's a nurse here called Jeff who's really nice. You'd like Jeff. He's really nice. I like them all. Isaad is absolutely lovely. He's a smashing fella. He comes from the Middle East. ... [Although] I don't go out much. No. No. No. I'd like to get out a bit more in the sunshine. I'd like to go out a bit more but I don't actually get out much. (Jude: service user/survivor)

Jude also reports that he has very little contact with other service users/survivors who live with him in shared accommodation. For Jude, his relationships are primarily with care staff as he finds it difficult to form friendships with service users/survivors living in his residential care unit. Jude describes his daily routine as consisting of either sitting in a corridor or in the TV area in between mealtimes. William also describes very rarely leaving his current residential care unit, although he is part of a service user committee which gives feedback to staff on service user experiences. What is particularly interesting about William's narrative is his comparison between his experience in residential care and his experience in psychiatric hospitals. For William, life in a psychiatric hospital was far more oppressive than his current life within a residential care home. He describes those experiences as far more negative due to his day-to-day existence being completely dictated to him by the hospital regime. William makes reference to how he decided to change his behaviour to prevent him from being admitted again to a psychiatric hospital. As he states:

Well I've spent most of the time since I was first in [a psychiatric hospital] feeling sorry for myself. I'm mentally ill and angry and all that kind of thing, but there was a point on the [psychiatric] ward that I said to myself, 'If you don't behave yourself William, you're going to be here for years'. So I made a point of behaving myself, doing whatever was required by the staff, befriending the staff, befriending people. (William: service user/survivor)

For William this was a conscious decision, where he participated in the hospital 
regime in order to be released. He illustrates the importance of conforming within the hospital regime and developing positive relationships with hospital staff. For William this has been a very successful strategy and he reports not returning to hospital in recent years. William suggests that he applies this strategy within his residential care unit to make sure he does not end up back in hospital. It is in this narrative where we observe William making a conscious decision to change his rebellious performances into socially acceptable performances, which are dictated to him by the hospital/care regime (Goffman, 1961; Foucault, 2003). Interestingly, all service users/survivors described contemporary psychiatric hospitalisation as unpleasant. However, when discussing bullying or intimidating behaviour by staff, service users/survivors agreed that this very rarely happens anymore. For Jack, he felt that this type of behaviour was far more likely to be instigated by other service users/survivors than by members of staff on psychiatric wards. When discussing how their lives have changed, all participants agreed that their experiences have improved since the 1980s.

When examining the experiences of service users/survivors there seems to be an element of institutional conformity within these narratives. The interactions and perceptions presented by service users/survivors seem to be affected by the institutional setting within which they are housed. From a service user/survivor perspective there is a narrative of improvement in care provision, but this idea is questioned by Christopher, who was a mental health nurse and then worked within community services. For Christopher, the closing of the mental hospitals and the opening of residential units in the 1990s was more to do with privatisation than improvement to services. When comparing professional practice in residential care with that of the historical mental hospitals, he suggests that:

It's just shit.... They [service users] are just now in the same kind of shitty plastic chairs but in [a residential care unit]. They'll never get out. They sit with their backs to the walls and they look. We [professionals] have just moved them to somewhere else. We haven't done anything with their lives. (Christopher: senior community practitioner)

Within this narrative there is some evidence of what Szasz (2005) refers to as trans-institutionalisation. From this perspective, contemporary health services have replaced the old larger institutions with smaller institutions, which are now referred to as residential care homes. From Christopher's perspective, the living conditions within these institutions have not significantly changed, although this was disputed by service users/survivors. From Christopher's perspective, the same structured daily activities, regimental systems of control and institutionalising processes are still in place. Within the narratives of participants, their descriptions of contemporary hospital/residential care have strong similarities to Goffman's definition of a total institution (Goffman, 1961). For participants in residential care, their daily lives were controlled through an institutional system, where participants would wake 
up, get dressed, eat and sleep at defined times. Although these participants had the opportunity of leaving the care homes, only one participant regularly went out. Participants in residential care were forced to conform to the institutional regime and, as discussed in the previous section, medication was used frequently. Although participants did not report experiencing violence, they were expected to conform or be 'sectioned' by being sent to a psychiatric hospital. Therefore service user/ survivor interactions were controlled through a set of administrative procedures which dominated service users'survivors' lives in this study (Goffman, 1961).

\section{Conclusion}

As Menzies et al. (2013) state, the emerging field of Mad Studies has developed out of a number of academic perspectives that are critical of psychiatry and its pathological classification of mental distress. Mad Studies academics have drawn influence from a number of critical disciplines including critical disability studies, mad activism and anti-psychiatry scholarship. In Brenda LeFrancois' (2017) seminar entitled 'Mad Studies: Maddening Social Work', she suggests the fundamental idea of Mad Studies is to produce knowledge from service users'/survivors' experiences and perceptions. However, she states that this act is fundamentally different from the neoliberal tokenistic rhetoric of service user involvement that currently exists in social work, where voices are used to reinforce professional practice. LeFrancois (2017) asserts that Mad Studies produces knowledge from mad activists, mad scholars, mad practitioners and their allies to generate theoretically relevant explanations of mental distress, in order to develop appropriate anti-oppressive practices and services to support people experiencing mental distress.

This study has utilised psycho-political theorists from within Mad Studies, alongside anti-psychiatry scholars, to explore the subjective histories of service users/survivors. Emerging from the lived experiences of service users/survivors the data findings expose examples of harmful and oppressive practices in mental health services. This study presents data corresponding with Laing's conceptualisation of the family, as it is in this space where the loss of self can start to occur. By drawing on anti-psychiatry scholars such as Laing and Goffman (1971) the findings suggest that the family can be conceptualised as a cultural space which works to socialise individuals through dominant normative ideologies. For Laing (1971) it is in this space where social roles and performances are learnt through the notion of normality which constructs the presentation of self (Goffman, 1959). It should be noted that the findings are not an attempt to blame individual family members for the onset of mental distress, but rather to critically analyse the family as a space which fosters dominant neoliberal ideologies that produce culturally specific normative behaviours. 
As service users'survivors' biographical narratives progressed, and their experiences of mental distress were classified as an 'illness', their behaviours were subsequently pathologised. As the data findings reveal, service users'/survivors' experiences of health care led them to be medicalised and institutionalised through a range of disciplinary regimes (Foucault, 1967; Szasz, 2007). This study illustrates that, for service users/survivors in this study, mental distress was disciplined through the use of psychoactive/psychotropic medications. From a Foucauldian perspective the distressed performances of participants are distorted by medication to produce culturally acceptable normative behaviours. However, for the majority of participants in this study these normative behaviours were confined to an institutional setting of either a hospital or a residential care home.

For participants in this study smaller care units have replaced larger mental hospitals, which seemed to have resulted in long-term institutionalisation for service users/survivors. Although participants acknowledge positive improvements to their living conditions, they also revealed elements of institutional power, as their perceptions and interactions seem to be significantly affected by the institutional setting in which they were housed (Goffman, 1961; Foucault, 1967; 1977). Similar to Goffman's description of a total institution, patient interactions were controlled through a set of administrative procedures, which dominated participants' lives. The data findings seem to confirm that health and social care practices are overshadowed by psychiatric practice where medication and hospitalisation have significantly shaped and structured service users'survivors' adult biographies.

To conclude, this study constructs mental distress as 'real', but the authors propose that these experiences should be reframed as social rather than pathological. As the findings reveal, significant problems emerged with the pathological explanation of 'mental illness', as biomedical practice did not result in 'cure' but in institutionalisation for service users/survivors in this study. Yet, Mad Studies is not just a critique of psychiatry but is also a theory relevant to social work practice. As Le Francois (2017) suggests, social work practitioners have become implicit in the psychiatrisation and treatments of service users/survivors. She asserts that social workers have abandoned their social expertise in this practice and allowed psychiatry to remain dominant over mental health services.

As LeFrancois (2017) proposes, by applying a Mad Studies perspective in social work, practitioners must allow safe spaces to bring together service users/ survivors to facilitate anti-oppressive treatments. Social workers must abandon the assumption that their own professional knowledge should surpass the knowledge of service users/survivors. The authors would argue that the desired role of a social worker is to facilitate self-actualisation rather than pathologising individuals who are experiencing mental distress. Therefore, Mad Studies may offer social workers a pathway back to a professional practice that champions human rights and challenges oppressive practice, rather than the recently acquired neoliberal model that manages medicalised care packages in the 'community'. 


\section{References}

The American Psychiatric Association (2013) The Diagnostic and Statistical Manual of Mental Disorders (5th Edn). Arlington: The American Psychiatric Association.

Bertaux, D. (2003) The usefulness of life stories for a realist and meaningful sociology. In R. Humphrey, R. Miller and E. Zdravomyslova (Eds.) Biographical Research in Eastern Europe: Altered lives and broken biographies. London: Ashgate (pp. 39-52).

Cowen, P., Harrison, P. and Burns, T. (2012) Shorter Oxford Textbook of Psychiatry. Oxford: Oxford University Press.

Deacon, L. (2017) Introduction to social work theory. In L. Deacon and S.J. Macdonald (Eds.) Social Work Theory and Practice. London: Learning Matters, Sage

Esposito, L. and Perez, F.M. (2014) Neoliberalism and the commodification of mental health. Humanity \& Society, 38, 4, 414-442

Faulkner, A. (2017) Survivor research and mad studies: The role and value of experiential knowledge in mental health research. Disability \& Society, 32, 4, 500-520.

Foucault, M. (1967) Madness and Civilisation. London: Tavistock.

Foucault, M. (1977) Discipline and Punish. London: Routledge.

Foucault, M. (2003) Abnormal: Lectures at the Collège de France 1974-1975. London: Verso.

Goffman, E. (1959) Presentation of Self. Harmondsworth: Penguin.

Goffman, E. (1961) Asylums. Harmondsworth: Penguin.

Goffman, E. (1964) Stigma: Notes on the management of spoiled identity. New Jersey: Prentice Hall.

Kafai, S. (2013) The mad border body: A political in-betweeness. Disability Studies Quarterly, 33, 1, ISSN:1041-5718 (Print), 2159-8371 (Online) [Accessed on 5 June 2018 at http:// dsq-sds.org/article/view/3438]

Kelly, S. and McKenna, H. P. (2004) Risks to mental health patients discharged into the community. Health, Risk \& Society, 6, 4, 376-385

Laing, R.D. (1959) The Divided Self. London: Penguin Books.

Laing, R.D. (1967) The Politics of Experience and the Bird of Paradise. London: Penguin Books. Laing, R.D. (1971) The Politics of the Family and Other Essays. London: Tavistock.

LeFrancois, B.A. (2017) Mad studies: Maddening social work. Seminar presented at Connecting for Canada's 150th: Canadian Visionaries of Critical Social Work, 16-19 November 2017, St Thomas University, Frederichton, New Brunswick [Accessed on 30 May 2018 at https:// www.youtube.com/watch?v=QYxM_bBk7fs].

LeFrancois, B.A., Menzies, R. and Reaume, G. (2013) Mad Matters: A critical reader in Canadian mad studies. Toronto: Canadian Scholar's Press.

Lewis, L. (2017) A Mad fight. In L. Davis (Ed.) The Disability Studies Reader, 5th edn. London: Routledge (pp. 102-118).

Marina, M. (2013) Recovery. In B. LeFrancois, R. Menzies and G. Reaume (Eds.) Mad Matters: A Critical Reader in Canadian Mad Studies. Toronto: Canadian Scholar's Press.

Mental Health Act (1983). London: Her Majesty's Stationery Office.

Mental Health Act (2007). London: Her Majesty's Stationery Office. 
Menzies, R., LeFrancois, B.A. and Reaume, G. (2013) Introducing mad studies. In B.A. LeFrancois, R. Menzies \& G. Reaume (Eds.) Mad Matters: A critical reader in Canadian mad studies. Toronto: Canadian Scholar's Press (pp. 1-22).

Porter, R. (2006) The Cambridge History of Medicine. Cambridge: Cambridge University Press.

Scott, S. and Thorpe, C. (2006) The sociological imagination of R.D. Laing. Sociological Theory, 24, 4, 331-352.

Scull, A. (2014) Madness in Civilization: A cultural history of insanity from the Bible to Freud, from the madhouse to modern medicine. London: Thames and Hudson Ltd.

Sedgwick, P. (1987) Psycho Politics. London: HarperCollins

Semple, D. and Smyth, R. (2013) Oxford Handbook of Psychiatry (3 ${ }^{\text {rd }}$ Edn). Oxford: Oxford University Press.

Szasz, T. (1961) The Myth of Mental Illness. St Albans: Paladin.

Szasz, T. (2005) 'Idiots, infants, and the insane': mental illness and legal incompetence. Journal of Medical Ethics, 31, 78-81

Szasz, T. (2007) Coercion as Cure: A critical history of psychiatry. London: Transaction Publishers.

Wengraf, T. (2001) Qualitative Research Interviewing. London: Sage. 